\title{
Efeito do Arrefecimento Causado pelo Fluido Durante a Soldagem em Operação em Tubulações com Espessura de Parede de 6 e $11 \mathrm{~mm}$
}

\author{
Jefferson Pinto Soares ${ }^{1}$, Paulo Faria ${ }^{1}$, Ronaldo Paranhos ${ }^{2}$ \\ 1 PETROBRAS, Unidade de Operações de Exploração e Produção na Bacia de Campos - UO/BC, Macaé, RJ, Brasil. \\ 2 Universidade Estadual do Norte Fluminense Darcy Ribeiro - UENF, Centro de Ciência e Tecnologia - CCT, Laboratório de \\ Materiais Avançados - LAMAV, Campos dos Goytacazes, RJ, Brasil.
}

Recebido: 10 Jul., 2017

Aceito: 03 Out., 2017

E-mails: jeffersonpsoares@petrobras. com.br(JPS), paulofaria56@gmail.com (PF), paranhos@uenf.br (RP)
Este é um artigo publicado em acesso aberto (Open Access) sob a licença Creative Commons Attribution Non-Commercial, que permite uso, distribuição e reproduçăo em qualquer meio, sem restriçōes desde que sem fins comerciais e que 0 trabalho original seja corretamente citado.
Resumo: Este trabalho compara a influência do arrefecimento causado por um fluído em circulação e em contato com a parede interna de uma tubulação, que caracteriza a soldagem em operação. Foram avaliadas duas espessuras de parede do tubo e duas temperaturas do fluido interno. A soldagem foi realizada na ligação de conexões de aço ASTM A105 a um tubo API 5L Gr X60 com espessura de $11 \mathrm{~mm}$ e de $6 \mathrm{~mm}$, utilizando os processos TIG (GTAW) e eletrodo revestido (SMAW). A circulação do fluido foi feita com água potável em duas faixas de temperatura, de 6 a $10{ }^{\circ} \mathrm{C}$ e 18 a $36{ }^{\circ} \mathrm{C}$. Durante a soldagem, a temperatura interna do tubo e a taxa de resfriamento foram monitoradas. Foram preparadas quatro juntas soldadas, avaliadas por ensaios não destrutivos (inspeção visual, líquido penetrante, partículas magnéticas e ultrassom), ensaios destrutivos (tração, dobramento, impacto, fratura e dureza) e análise macrográfica e micrográfica. Os resultados mostram que, com os procedimentos adotados, não é necessária a adoção de cuidados especiais quanto à possibilidade de perfuração e vazamento de fluido durante a soldagem em operação. Houve evidencias que o efeito do arrefecimento do fluido no interior do tubo foi mais significativo que a espessura da parede do tubo no aumento da taxa de resfriamento. Ainda, a temperatura do fluido em circulação no tubo exerceu papel secundário no aumento da taxa de resfriamento e na redução da temperatura máxima na parede interna do tubo. O arrefecimento causado pelo fluido provocou aumento na dureza da ZF e ZTA, reduziu o alongamento no ensaio de tração, porém ainda em valores adequados. Estes comportamentos foram mais observados no tubo de menor espessura, de $6 \mathrm{~mm}$. Foi possível, pelos resultados dos ensaios não destrutivos e ensaios mecânicos obtidos, qualificar os procedimentos de soldagem, com base nas normas especializadas neste processo.

Palavras-chave: Soldagem em operação; Arrefecimento; TIG; Eletrodo revestido.

\section{Effect of Freezing Caused by Fluid during In-service Welding of Pipes with Wall Thickness of 6 and $11 \mathrm{~mm}$}

\begin{abstract}
This work compares the influence of cooling caused by a circulating fluid and in contact with the inner wall of a pipe, which characterizes the in-service welding. There were evaluated two wall thicknesses of the pipe and two temperatures of the inner fluid. The welding was done to join connections of ASTM A105 steel to an $11 \mathrm{~mm}$ and $6 \mathrm{~mm}$ thick API 5L Gr X60 steel pipe, using TIG (GTAW) and stick electrode (SMAW) processes. The circulation of the fluid was made with potable water within two temperature ranges, of 6 to $10{ }^{\circ} \mathrm{C}$ and 26 to $36^{\circ} \mathrm{C}$. During welding, the inner temperature of the pipe and the cooling rate were monitored. Four welded joints were prepared, evaluated by non-destructive tests (visual inspection, penetrating liquid, magnetic particles and ultrasonic), destructive testing (tensile, bending, impact Charpy $\mathrm{V}$, fracture and hardness), macrographic and micrographic analysis. The results show that, with the adopted procedures, it is not needed the adoption of any special cares regarding the possibility of perforation and leaking of fluid during in service welding. There were evidences that the effect of the fluid freezing inside the pipe was more significant than the pipe wall thickness in order to increase the cooling rate. Still, the temperature of the fluid circulaling the pipe had a secondary effect in the increase of cooling rate and in the reduction of the maximum temperature in the inner wall of the pipe. The freezing caused by the fluid promoted an increase in hardness of both fusion zone and heat affected zone, reduced elongation in the tension test, but still with adequate values. With the results of non destructive and mechanical tests was possible to qualify welding procedures, based on the standards specialized in this process.
\end{abstract}

Key-words: In-service welding; Freezing; GTAW; SMAW. 


\section{Introdução}

A soldagem em operação é um procedimento realizado quando o equipamento em que se está soldando encontra-se em regime de serviço. Geralmente é aplicada quando há a necessidade de algum tipo de reparo ou adaptações onde não é possível efetuar a parada do equipamento ou, o custo da parada é muito elevado.

A diferença básica que pode ser assinalada na soldagem de dutos em operação da soldagem de fabricação de dutos, diz respeito a taxa de resfriamento, pois o fluido em circulação promove altas taxas de extração de calor. Ainda deve-se atentar ao risco de perfuração quando se está executando a soldagem em tubos de parede fina, mais ainda quando o fluido em circulação é inflamável, caso típico da indústria do petróleo [1].

Há dois riscos potenciais a serem considerados na soldagem em operação: a formação de trincas a frio e o excesso de penetração do cordão de solda na parede do duto, podendo causar a perfuração do tubo.

As trincas a frio podem surgir devido à alta concentração de hidrogênio na solda (proveniente do revestimento dos eletrodos, caso não recebam tratamento adequado), a uma microestrutura susceptível (martensita ou bainita), à presença de tensões residuais elevadas e à baixa temperatura [2]. É característica de processos de soldagem de baixa energia, podendo ocorrer na zona termicamente afetada (ZTA) e na zona fundida (ZF) [3].

A perfuração da tubulação poderá ocorrer caso a seção remanescente adjacente à poça de fusão não tenha resistência suficiente para suportar as tensões resultantes da operação do duto [4]. O risco de perfuração não depende somente da penetração da parede, mas também dos parâmetros de soldagem (tensão, corrente, velocidade de soldagem) e das condições de operação do duto (vazão, pressão, temperatura e propriedades térmicas do fluido). O risco de penetração aumenta com o aumento da energia de soldagem e o risco da fissuração a frio é função do potencial de hidrogênio do processo de soldagem [5].

Processos de soldagem de baixo hidrogênio, tais como TIG e eletrodo revestido com revestimento tipo básico, associados a uma baixa energia de soldagem, resultam numa condição de menor penetração. Mas, na soldagem de tubos de espessura mais elevada, onde o risco de perfuração é menor, frequentemente são adotados aportes térmicos mais elevados, para minimizar o risco do aparecimento de trincas a frio.

Este trabalho é uma continuação de outro já publicado [6], que simulou a soldagem em operação envolvendo a união de conexões a tubos de $11 \mathrm{~mm}$ de espessura. Durante a soldagem, houve o fluxo continuo de água no interior do tubo em duas faixas de temperatura (ambiente e em torno de $10^{\circ} \mathrm{C}$ ). Neste trabalho, foram realizados procedimentos de soldagem em tubos de espessura mais fina, no caso $6 \mathrm{~mm}$, utilizando-se a mesma metodologia. Foram avaliadas as taxas de resfriamento, as propriedades mecânicas e as modificações microestruturais dos materiais provocados pela soldagem em operação. $O$ objetivo é então avaliar a influência do arrefecimento causado pelo fluído em circulação e em contato com a parede interna do tubo, bem como os efeitos no arrefecimento causados pela espessura do tubo e pela temperatura do fluido interno.

\section{Materiais e Métodos}

O tubo utilizado foi um API 5L X60 com diâmetro nominal 12" (323 mm) e espessura de parede de $11 \mathrm{~mm}$. Parte do tubo foi usinado radialmente para obtenção de espessura de $6 \mathrm{~mm}$. As conexões foram feitas com quatro chapas ASTM A572 Gr50 de espessura 22 mm, cuja composição química e soldabilidade são similares às conexões reais, fabricadas conforme a norma ASTM A105 [7]. A composição química destes materiais foi testada por análise com um espectrômetro de emissão óptica.

Soldagem: foram executadas quatro juntas de ângulo, com $500 \mathrm{~mm}$ de comprimento cada, soldadas com penetração total, cujo aparato experimental é mostrado na Figura 1. No intuito de avaliar os efeitos do resfriamento acelerado causado pelo fluido interno, foram testadas duas situações: uma com fluxo à temperatura ambiente e outra com o fluxo resfriado, abaixo de $10^{\circ} \mathrm{C}$. As soldas foram identificadas como: Q6 e Q11: uniões entre a chapa de $22 \mathrm{~mm}$ aos tubos de $6 \mathrm{~mm}$ e de $11 \mathrm{~mm}$ respectivamente, com o fluxo à temperatura ambiente; F6 e F11: uniões entre a chapa de $22 \mathrm{~mm}$ aos tubos de $6 \mathrm{~mm}$ e de $11 \mathrm{~mm}$ respectivamente, com o fluxo à temperatura abaixo de $10^{\circ} \mathrm{C}$; FS6 e FS11: uniões entre a chapa de $22 \mathrm{~mm}$ aos tubos de $6 \mathrm{~mm}$ e $11 \mathrm{~mm}$ respectivamente, sem fluxo interno, ou seja, soldagem convencional. 
Efeito do Arrefecimento Causado pelo Fluido Durante a Soldagem em Operação em Tubulações com Espessura de Parede de 6 e $11 \mathrm{~mm}$

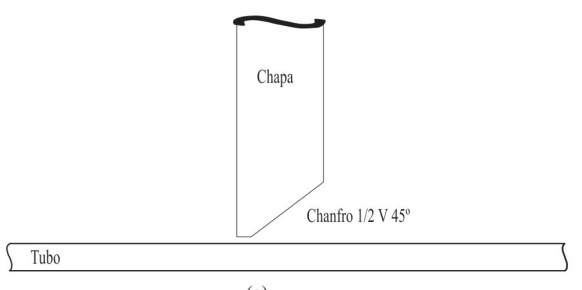

(a)

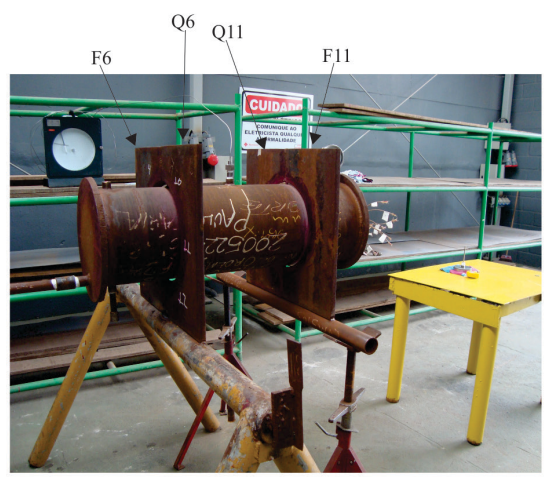

(b)

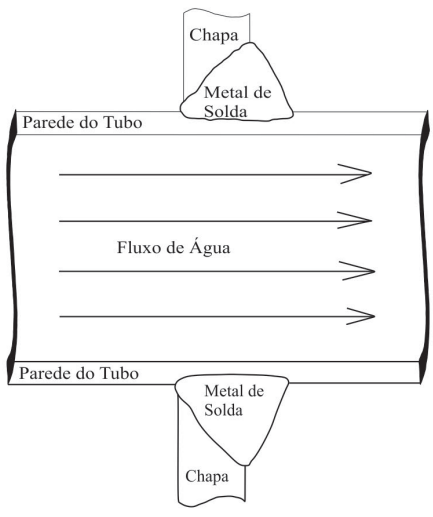

(c)

Figura 1. Detalhes do Aparato Experimental. (a) Detalhe da junta utilizada no experimento; (b) Aparato experimental e posição das soldas; (c) Detalhe da peça soldada mostrando o fluxo do líquido durante o experimento.

Os processos de soldagem utilizados foram TIG com corrente contínua polaridade direta (CCPD) no passe de raiz e reforço da raiz, utilizando varetas classe ER70S-3 [8] com gás de proteção Argônio 99,99\%. A seguir, foi utilizado eletrodo revestido classe E7018 [9], com corrente continua polaridade inversa (CCPI), para os passes de enchimento e acabamento. Os soldadores foram previamente qualificados, nos dois processos, em procedimento de soldagem convencional.

Controle Durante a Soldagem: A circulação do fluido no procedimento Q11 e Q6 foi realizada com água à temperatura ambiente. Nos procedimentos $F 11$ e F6, a circulação foi realizada com água resfriada artificialmente, com a adição de gelo picado na caixa d'água, que possibilitou durante toda a soldagem a temperatura do líquido do fluxo abaixo de $10^{\circ} \mathrm{C}$. As variáveis do fluxo no interior do tubo, como pressão, vazão, velocidade de escoamento e regime de escoamento foram mantidas fixas (veja Tabela 1). Durante a soldagem, as variáveis do processo foram medidas: intensidade de corrente e tensão com um multímetro; a velocidade de soldagem foi calculada pela relação entre o comprimento da solda e o tempo gasto para sua realização. Também foi medida a largura do cordão depositado (oscilação).

Tabela 1. Variáveis do fluxo no interior do tubo.

\begin{tabular}{lc}
\hline \multicolumn{1}{c}{ Fluido } & Água \\
Pressão do Fluido $\left(\mathrm{kg} / \mathrm{cm}^{2}\right)$ & 0,2 \\
Vazão do Fluido $(\mathrm{l} / \mathrm{s})$ & 0,6 \\
Velocidade de Escoamento do Fluido $(\mathrm{m} / \mathrm{s})$ & 0,002 \\
Número de Reynolds & 806 \\
Regime de Fluxo & Escoamento Laminar \\
\hline
\end{tabular}

O controle da temperatura do fluido foi realizado utilizando um termômetro analógico, instalado no tubo o próximo à entrada de água, como mostra a Figura 2 (a). O registro destas temperaturas foi feito, de forma continua, através de termorregistrador ligado a um termopar, que foi instalado no meio do tubo, na parte superior (veja Figura 2 (a)). Serão apresentadas apenas as temperaturas máximas e mínimas registradas. 


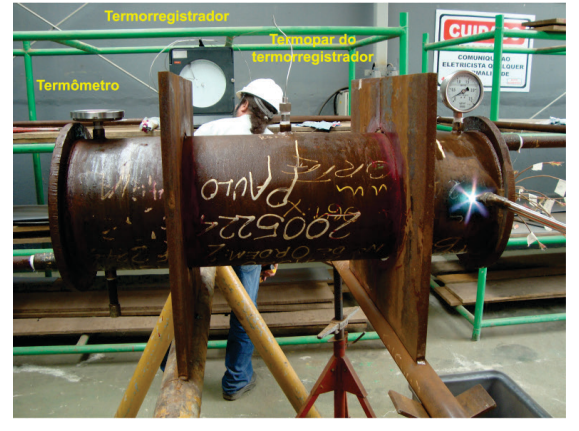

(a)

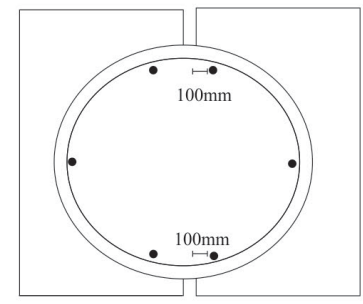

(b)

Figura 2. Detalhes dos instrumentos utilizados para a monitoração da temperatura. (a) Termômetro, termopar e termo-registrador; (b) posição de instalação dos temopares internos.

A temperatura na peça foi medida tanto pelo lado interno, em contato com o fluído, como pelo lado externo, onde a solda foi realizada. Pelo lado interno do tubo, na parede do tubo sob a solda, foram instalados 3 termopares do tipo $\mathrm{K}$ em cada junta soldada, totalizando 6 termopares, acoplados a um termoregistrador, como mostrado na Figura 2 (b). A instalação foi feita antes da montagem do aparato e a fixação dos termopares foi efetuada pelo método de solda por pontos. O objetivo foi registrar as temperaturas máximas e mínimas atingidas durante a soldagem, no interior do tubo, na região sob a solda. Pelo lado externo do tubo, foi usado um pirômetro ótico para medir a temperatura entre passes e a temperatura das peças durante a soldagem.

A taxa de resfriamento da peça $\left(\Delta \mathrm{T}_{350-150}\right)$ entre $350^{\circ} \mathrm{C}$ e $150^{\circ} \mathrm{C}$ foi estimada conforme critério da norma API 1104 [10]. A metodologia usada consistiu em aquecer localmente o tubo em uma região próxima à solda, utilizando um maçarico oxi-acetileno como fonte de calor, como mostrado na Figura 2 (a). 0 tubo foi aquecido até $400^{\circ} \mathrm{C}$, em seguida a chama foi interrompida e iniciou-se a contagem do tempo de resfriamento a partir de $350^{\circ} \mathrm{C}$ até $150^{\circ} \mathrm{C}$, usando um pirômetro ótico e um cronômetro. A taxa de resfriamento foi calculada em ${ }^{\circ} \mathrm{C} / \mathrm{s}$. Foram realizadas seis medições, sendo calculada a média dos resultados. Este procedimento foi realizado para as duas espessuras do tubo ( $11 \mathrm{~mm}$ e $6 \mathrm{~mm}$ ) e para as duas temperaturas do fluido (temperatura ambiente e $10^{\circ} \mathrm{C}$ ). Também foi medida para os tubos sem fluxo interno, que representa o procedimento de soldagem convencional, ou seja, sem fluido de arrefecimento, para efeito de comparação.

Ensaios Não Destrutivos: após a soldagem, 100\% das juntas soldadas foram submetidas à inspeção visual, líquido penetrante, partículas magnéticas e ultrassom. Os ensaios foram conduzidos de acordo com a norma ASME Section V [11] por inspetores qualificados.

Ensaios Mecânicos: Todas as juntas foram avaliadas, por meio dos ensaios de impacto Charpy $V$, tração transversal, fratura, dureza e dobramento. A Tabela 2 mostra a quantidade de corpos de prova usados. Os ensaios foram programados com base nas especificações de fabricação dos materiais e nas normas aplicáveis na qualificação dos procedimentos de soldagem, no caso as normas API 1104 [10] e ASME Seção IX [12]. A localização e orientação para a retirada dos corpos de prova são mostradas na Figura 3. Os ensaios foram conduzidos de acordo com a norma ASTM A 370 [13], seguindo os critérios de aceitação referentes à qualificação destes procedimentos de soldagem, ASME IX [12] e API 1104 [10].

Tabela 2. Ensaios destrutivos realizados.

\begin{tabular}{|c|c|c|c|c|c|c|}
\hline Ensaios & Total de CP & Q11 & F11 & Q6 & F6 & Metal Base \\
\hline Tração & 9 & 2 & 2 & 2 & 2 & 1 \\
\hline Dobramento & 16 & 4 & 4 & 4 & 4 & - \\
\hline Impacto & 27 & 6 & 6 & 6 & 6 & 3 \\
\hline Fratura & 16 & 4 & 4 & 4 & 4 & - \\
\hline Dureza & 20 & 5 & 5 & 5 & 5 & - \\
\hline
\end{tabular}


Efeito do Arrefecimento Causado pelo Fluido Durante a Soldagem em Operação em Tubulações com Espessura de Parede de 6 e $11 \mathrm{~mm}$
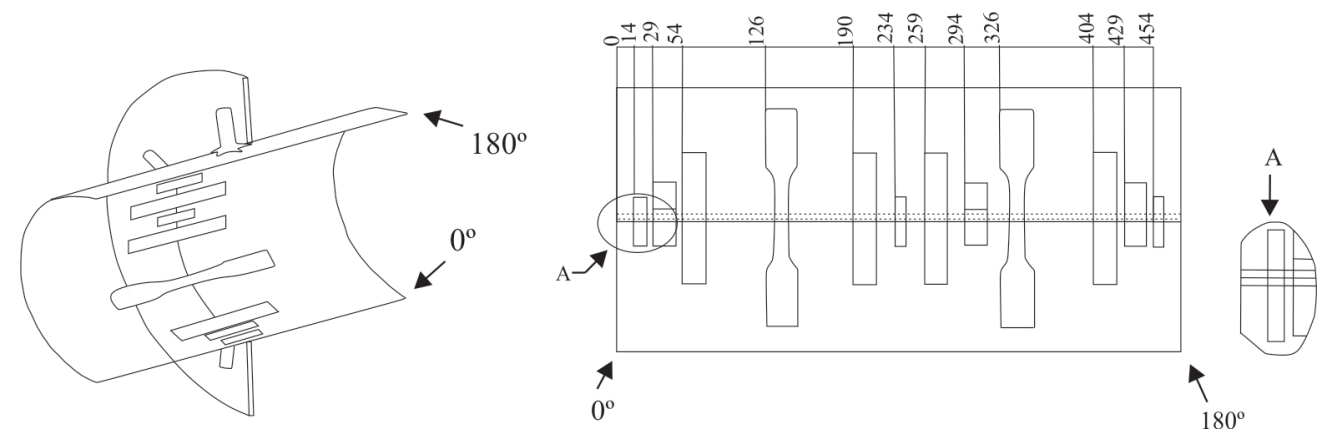

Figura 3. Orientação e localização para retirada dos CP's.

Ensaio de Impacto Charpy V: para cada junta soldada foram preparados 6 corpos de prova (CP's), sendo $3 \mathrm{com}$ entalhe no centro da solda e 3 na ZTA próxima a região de grãos grosseiros. A dimensão destes CP's foram de $55 \times 10 \times 7,4 \mathrm{~mm}$. Para o metal de base foram preparados 3 CP's com a dimensão padrão, de $55 \times 10 \times 10 \mathrm{~mm}$. Todos foram ensaiados à temperatura de $0^{\circ} \mathrm{C}$. Para a comparação dos resultados, a energia absorvida foi convertida por meio da Equação 1 abaixo:

$$
\text { Média Convertida }=\frac{(\text { Média } \times 10)}{\text { espessura }}
$$

Ensaio de Tração: o CP do metal base foi retirado no sentido longitudinal de laminação do tubo. Para cada junta soldada, 2 CP's transversais à solda foram preparados para cada procedimento.

Fratura (Nick Break): realizado em 16 CPs, 4 para cada procedimento. Este ensaio tem a finalidade de verificar a existência de descontinuidades internas.

Ensaio de Dobramento: realizado em 16 CPs, 4 para cada procedimento, tendo sido dobrada a face da solda, com a finalidade de avaliar a ductilidade da junta soldada.

Exame Macrográfico e Ensaio de Dureza vickers: o exame macrográfico foi realizado para identificar as regiões e extensão da ZTA, assim como a ocorrência de descontinuidades internas nas juntas soldadas. Cinco CP's foram preparados para cada junta soldada. As amostras foram cortadas, lixadas e atacadas com Nital $10 \%$ por cerca de 20 segundos. $O$ ensaio de dureza vickers foi realizado com carga de $10 \mathrm{kgf}$ nos corpos de prova de macrografia e conduzido conforme a norma ASTM E 92 [14]. Foram feitas medições de dureza em 22 pontos em cada macrografia, seguindo duas linhas com $1 \mathrm{~mm}$ de distância das bordas do CP, uma no lado da face e outra no lado da raiz, com 11 impressões de cada lado, como mostra a Figura 4. No total, foram 440 medições entre a chapa, o tubo, a ZTA e o metal de solda para as 2 juntas soldadas.

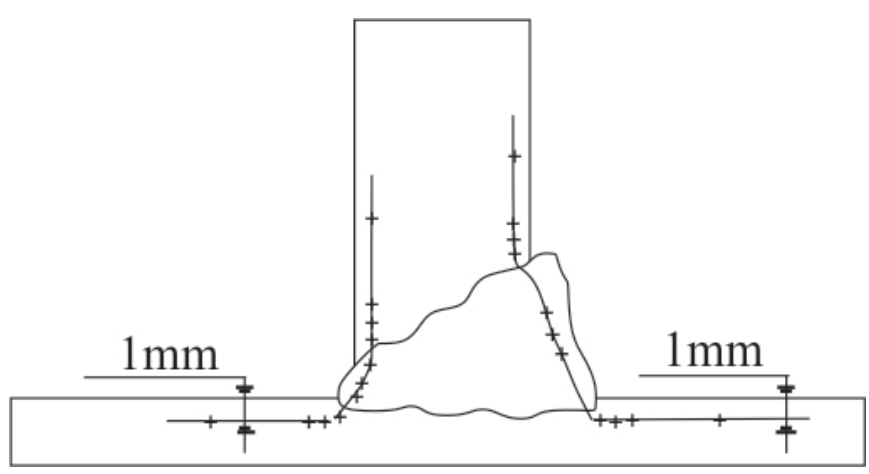

Figura 4. Arranjo para medição de dureza. 
Microestrutura: foi observada em microscópio ótico (MO) com aumentos de 400X e 500X nas amostras F6 e Q11. O intuito foi identificar a microestrutura resultante do processo de soldagem com superesfriamento. A Figura 5 identifica os locais de remoção dos CP's. A região escolhida para análise foi a do último passe depositado, onde não houve a deposição posterior de cordões de solda, ou seja, sem sofrer reaquecimento.

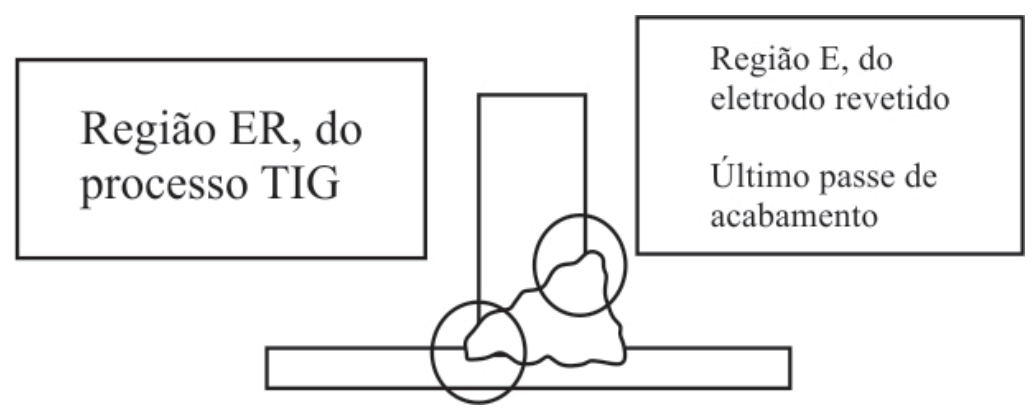

Figura 5. Região das amostras para micrografia.

\section{Resultados e Discussão}

Análise Química: a Tabela 3 mostra que a composição química do tubo atendeu às exigências da norma API $5 \mathrm{~L}$ para este material. $O$ carbono equivalente (CE) foi calculado conforme indicado na Tabela 3 em 0,42\%, próximo do limite máximo previsto para o grau X-60, que é de $0,43 \%$. A composição da chapa ASTM A105 [7] também atendeu à especificação, com CE calculado em $0,42 \%$, sendo o máximo permitido de $0,48 \%$ para este material. Tanto o tubo como a chapa foram cuidadosamente escolhidos para este trabalho, de forma que o CE de ambos estivessem próximos ao limite máximo das especificações, pois na soldagem, altos valores de CE implicam em uma maior susceptibilidade a formação de estruturas frágeis e trincas a frio [3].

Tabela 3. Composição Química dos Materiais de Base.

\begin{tabular}{|c|c|c|c|c|}
\hline \multicolumn{5}{|c|}{ Composição Química } \\
\hline \multirow{2}{*}{ Elemento } & \multicolumn{2}{|c|}{ Tubo } & \multicolumn{2}{|c|}{ Chapa } \\
\hline & Ensaio & Norma API 5L & Ensaio & Norma ASTM A105 \\
\hline C (\%) & 0,188 & 0,24 máx & 0,22 & 0,35 máx \\
\hline $\mathrm{Mn}(\%)$ & 1,24 & 1,40 máx & 1,17 & 1,35 máx \\
\hline $\mathrm{Cr}(\%)$ & 0,007 & - & 0,017 & 0,30 máx \\
\hline Mo (\%) & 0,044 & - & 0,002 & 0,12 máx \\
\hline V (\%) & 0,054 & 0,10 máx & 0,001 & 0,08 máx \\
\hline $\mathrm{Ni}(\%)$ & 0,05 & - & 0,002 & 0,40 máx \\
\hline $\mathrm{Cu}(\%)$ & 0,003 & - & 0,003 & 0,40 máx \\
\hline $\mathrm{CE}(\%)$ & 0,42 & 0,43 máx & 0,42 & 0,48 máx \\
\hline \multicolumn{5}{|c|}{$\mathrm{CE}(\%)=(\% C)+\frac{(\% M n)}{6}+\frac{(\% C r)+(\% V)+(\%(M o)}{5}+\frac{(\% N i)+(\% C u)}{15}$} \\
\hline
\end{tabular}

Execução da Soldagem: a Tabela 4 mostra os parâmetros de soldagem utilizados e o cálculo do aporte de calor (HI) conforme a Equação 2 abaixo.

$$
H I(\mathrm{~kJ} / \mathrm{cm})=0,06 \times \frac{\text { corrente }(A) \times \text { tensão }(V)}{\text { velocidade }(\mathrm{cm} / \mathrm{min})}
$$


Efeito do Arrefecimento Causado pelo Fluido Durante a Soldagem em Operação em Tubulações com Espessura de Parede de 6 e $11 \mathrm{~mm}$

Tabela 4. Informações sobre os procedimentos de soldagem.

\begin{tabular}{|c|c|c|c|c|c|c|c|}
\hline 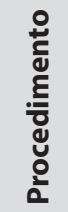 & $\begin{array}{l}\text { Local da Solda } \\
\text { e Processo de } \\
\text { Soldagem }\end{array}$ & $\begin{array}{c}\text { Tipo de } \\
\text { corrente / } \\
\text { Polaridade }\end{array}$ & Tensão (V) & Corrente (A) & $\begin{array}{c}\text { Velocidade } \\
\text { (cm/min) }\end{array}$ & $\begin{array}{l}\text { Oscilação } \\
(\mathbf{m m})\end{array}$ & $\begin{array}{l}\text { Aporte } \\
\text { de Calor } \\
(\mathrm{kJ} / \mathrm{cm})\end{array}$ \\
\hline \multirow{4}{*}{ Q6 } & Raiz (TIG) & CCPD & 12 & 167 & 4,2 & 8,7 & 28,6 \\
\hline & Reforço (TIG) & CCPD & 13 & 131 & 11 & 9,3 & 9,3 \\
\hline & Enchimento (ER) & CCPI & $23-28$ & $115-154$ & $8-17$ & $7-11$ & 23,5 \\
\hline & Acabamento (ER) & CCPI & $26-28$ & $90-100$ & $10-17$ & $9-10$ & 16,8 \\
\hline \multirow{4}{*}{ Q11 } & Raiz (TIG) & CCPD & 13 & 148 & 3 & 7 & 38,5 \\
\hline & Reforço (TIG) & CCPD & 11,5 & 141 & 6 & 8 & 16,2 \\
\hline & Enchimento (ER) & CCPI & $24-26$ & $140-150$ & $10-22$ & $7-10$ & 21,0 \\
\hline & Acabamento (ER) & CCPI & 26 & 100 & $11-20$ & $7-8$ & 14,2 \\
\hline \multirow{4}{*}{ F6 } & Raiz (TIG) & CCPD & 13 & 152 & 3,5 & 7,5 & 33,9 \\
\hline & Reforço (TIG) & CCPD & 15 & 224 & 9,2 & 8,2 & 21,9 \\
\hline & Enchimento (ER) & CCPI & $26-31$ & $117-140$ & $8-20$ & $7-10$ & 28,3 \\
\hline & Acabamento (ER) & CCPI & 25 & 120 & $14-18$ & $7-9$ & 13,1 \\
\hline \multirow{4}{*}{ F11 } & Raiz (TIG) & CCPD & 14 & 205 & 7,5 & 7,1 & 23,0 \\
\hline & Reforço (TIG) & CCPD & 15,2 & 226 & 12 & 10 & 17,2 \\
\hline & Enchimento (ER) & CCPI & $25-29$ & $130-150$ & $7-20$ & $9-11$ & 30,1 \\
\hline & Acabamento (ER) & CCPI & $28-30$ & $100-105$ & $11-17$ & $8-9$ & 15,8 \\
\hline
\end{tabular}

Ensaios Não Destrutivos: foram realizados de acordo com os métodos previstos. Ensaio visual, LP e PM não mostraram evidências de descontinuidades. O ensaio de US não detectou defeitos internos. As juntas foram consideradas aprovadas conforme os critérios de aceitação das normas ASME B 31.3 [15], ASME seção IX [12] e API 1104 [10].

Controle da Temperatura durante a Soldagem: a Tabela 5 mostra que a temperatura do fluido interno ficou entre 26 e $36{ }^{\circ} \mathrm{C}$ para o procedimento $\mathrm{Q} 11$ e entre 18 e $30^{\circ} \mathrm{C}$ para o procedimento Q6. Já o procedimento $\mathrm{F} 11$ o fluido ficou entre 6 e $10^{\circ} \mathrm{C}$ e no procedimento $\mathrm{F} 6$ variou entre 7 e $10{ }^{\circ} \mathrm{C}$. Desta forma, conclui-se que durante os experimentos foi possível manter as faixas de temperatura do flúido pré-estabelecidas.

Tabela 5. Intervalos das temperaturas registradas durante a soldagem.

\begin{tabular}{cccccccc}
\hline Temperatura $\left({ }^{\circ} \mathbf{C}\right)$ & & Q6 & Q11 & F6 & F11 & SF6 & SF11 \\
Do fluido interno $\left({ }^{\circ} \mathrm{C}\right)$ & Mínima & 18 & 26 & 7 & 6 & - & - \\
& Máxima & 30 & 36 & 10 & 10 & - & - \\
Externa no tubo, próximo à solda $\left({ }^{\circ} \mathrm{C}\right)$ & Mínima & 17 & 25,6 & 4,8 & 6,7 & - & - \\
& Máxima & 29 & 31,8 & 10,4 & 10 & - & - \\
Interna da parede do tubo $\left({ }^{\circ} \mathrm{C}\right)$ & Mínima & 465 & 221 & 335 & 250 & - & - \\
& Máxima & 558 & 338 & 442 & 298 & - & - \\
\hline $\mathbf{\Delta t ~}(\mathbf{3 0 0}-\mathbf{1 5 0})\left({ }^{\circ} \mathbf{C} / \mathbf{s}\right)$ & & 55 & 37,5 & 62 & 50 & 1,2 & 2 \\
\hline
\end{tabular}

Em relação à temperatura externa do tubo, próximo a solda, na Tabela 5 verifica-se muito pouca influência tanto da espessura do tubo (ao comparar as soldas Q6 com Q11 e F6 com F11) quanto da temperatura do flúido (ao comparar as soldas Q11 com F11 e Q6 com F6).

Em relação a temperatura interna da parede do tubo, a Tabela 5 mostra os máximos e mínimos obtidos, e pode ser observado que: 
i) A máxima temperatura interna da parede do tubo foi de $558^{\circ} \mathrm{C}$ no procedimento Q6. A norma N-2163 [16] especifica que, para evitar perfuração durante a soldagem em operação, a temperatura interna da parede deve ser inferior a $980^{\circ} \mathrm{C}$. Conclui-se que para todos os procedimentos, a temperatura interna máxima do tubo está bem abaixo da máxima especificada por norma, minimizando a possibilidade de perfuração durante a soldagem.

ii) Ao comparar o efeito da espessura do tubo (soldas Q6 com Q11 e F6 com F11), observa-se que para a menor espessura $(6 \mathrm{~mm})$, a temperatura interna atingida na parte interna do tubo é bem maior que para a espessura de $11 \mathrm{~mm}$.

iii) Ao comparar o efeito da temperatura do flúido interno (soldas Q11 com F11 e Q6 com F6), pode ser observado uma fraca tendência para a menor temperatura do fluido em reduzir a temperatura interna do tubo, porém bem menos pronunciado que no item ii) acima.

Em relação aos resultados da taxa de resfriamento ( $\Delta \mathrm{t}(300-150))$ na Tabela 5, pode ser observado que:

i) A taxa de resfriamento para as soldas convencionais (SF6 e SF11) foram muito inferiores às obtidas com a presença do fluido no interior do tubo. Isto mostra o forte efeito de arrefecimento provocado pelo fluido durante a soldagem em operação.

ii) Ao comparar o efeito da espessura do tubo (soldas Q6 com Q11 e F6 com F11), observa-se que as taxas de resfriamento para a menor espessura $(6 \mathrm{~mm})$ são ligeiramente maiores que para a espessura de $11 \mathrm{~mm}$.

iii) Ao comparar o efeito da temperatura do flúido interno (soldas Q11 com F11 e Q6 com F6), também foi observada uma tendência que as taxas de resfriamento são maiores para a menor temperatura do flúido.

Os resultados acima permitem concluir sobre as temperaturas máximas obtidas e as taxas de resfriamento no interior do tubo: i) nos procedimentos realizados, não houve risco de perfuração durante a soldagem; ii) o efeito do arrefecimento oferecido pelo flúido interno no tubo foi mais significativo que a temperatura deste flúido em reduzir as temperaturas máximas e aumentar a taxa de resfriamento e iii) uma menor espessura do tubo sendo soldado está associado a um incremento tanto na temperatura máxima obtida como na taxa de resfriamento.

Macrografia: a Figura 6 mostra, para o procedimento F6, as regiões da junta soldada, a quantidade de passes e camadas, a transição entre o metal de adição e o metal de base e identifica a extensão da ZTA. Todas as macrografias foram consideradas aprovadas.

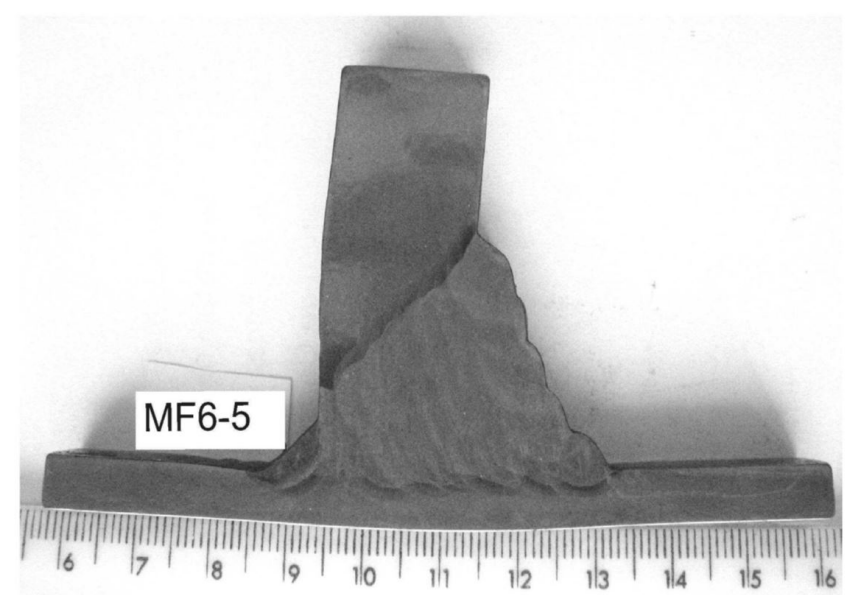

Figura 6. Macrografia típica, relativa ao procedimento F6.

Ensaio de Tração: a norma API 5L PSL-2 [17] especifica o alongamento mínimo para o material do tubo, que é atribuído em função da espessura do CP. Quanto menor a espessura do metal de base, conforme a norma, menor será o alongamento percentual. Assim foi determinado o mínimo alongamento percentual para as duas espessuras utilizadas, que foi de $20 \%$ para os CP com $11 \mathrm{~mm}$ e $17 \%$ para os CP com $6 \mathrm{~mm}$. A Tabela 6 mostra os resultados dos 
Efeito do Arrefecimento Causado pelo Fluido Durante a Soldagem em Operação em Tubulações com Espessura de Parede de 6 e $11 \mathrm{~mm}$

Tabela 6. Resultados dos Ensaios de Tração.

\begin{tabular}{|c|c|c|c|c|c|c|c|c|}
\hline & \multicolumn{2}{|c|}{ Escoamento (MPa) } & \multicolumn{2}{|c|}{ Resistência (MPa) } & \multicolumn{2}{|c|}{ Alongamento (\%) } & \multirow{2}{*}{$\begin{array}{c}\text { Redução de Área } \\
\text { (\%) }\end{array}$} & \multirow{2}{*}{ FRATURA } \\
\hline & Ensaio & Norma & Ensaio & Norma & Ensaio & Norma & & \\
\hline MB & 498 & \multirow{9}{*}{$\begin{array}{c}415 \\
\text { (Mín.) } \\
565 \\
\text { (Max) }\end{array}$} & 586 & \multirow{9}{*}{$\begin{array}{c}520 \\
\text { (Mín.) } \\
760 \\
\text { (Max) }\end{array}$} & 33,8 & 20 (Mín.) & 70,05 & - \\
\hline Q6 & 510 & & 582 & & 16,6 & & 64,15 & $\mathrm{MB}$ \\
\hline Q6 & 503 & & 586 & & 15,6 & 17 & 64,05 & MS \\
\hline F6 & 510 & & 578 & & 12,0 & (Mín.) & 66,93 & MB \\
\hline F6 & 492 & & 567 & & 12,4 & & 67,40 & MB \\
\hline Q11 & 507 & & 590 & & 21,2 & & 62,24 & MB \\
\hline Q11 & 485 & & 535 & & 20,8 & 20 & 70,42 & MB \\
\hline $\mathrm{F} 11$ & 519 & & 605 & & 22,8 & (Mín.) & 56,78 & MB \\
\hline F11 & 515 & & 596 & & 19,2 & & 43,74 & MS \\
\hline
\end{tabular}

ensaios de tração realizados. De uma forma geral, observa-se uma relativa queda no alongamento das juntas soldadas, quando comparado ao metal base, atribuído ao efeito de arrefecimento do fluido. Tanto o tubo usado (metal base), como as juntas soldadas com $11 \mathrm{~mm}$ de espessura foram atendidos os requisitos da norma API 5L PSL-2 [17]. Já as amostras com $6 \mathrm{~mm}$ de espessura apresentaram uma redução de alongamento mais elevada do que a permitida pela norma. Esta queda mais acentuada na ductilidade foi atribuída ao aumento do arrefecimento em função da maior proximidade entre o fluido e a fonte de calor de soldagem, que proporcionou um aumento da temperatura interna máxima alcançada, assim como um aumento na taxa de resfriamento no tubo de menor espessura. Observa-se ainda que a temperatura do fluido teve efeito secundário para a redução da ductilidade.

Fratura (Nick Break): o objetivo deste ensaio é atestar a inexistência de defeitos nas juntas soldadas. Os ensaios dos 16 CP's não evidenciaram descontinuidades significativas, sendo considerados aprovados.

Ensaio de Dobramento: não foram constatadas descontinuidades acima de $3 \mathrm{~mm}$ na região de dobramento, sendo considerados aprovados conforme API 1104 [10].

Dureza Vickers: a Tabela 7 mostra os resultados de dureza obtidos (média, desvio padrão e coeficiente de variância). O valor máximo da média de dureza encontrado foi de 287 HV, para a zona fundida (ZF) da junta Q6. Os valores médios de dureza das juntas com espessura de $6 \mathrm{~mm}$ foram ligeiramente superiores aos das juntas de $11 \mathrm{~mm}$, atribuído ao maior arrefecimento causado pela maior proximidade do fluido com a fonte de calor (veja Tabela 5). Por outro lado, observa-se que a redução da temperatura do fluido interno de $26-36^{\circ} \mathrm{C}$ para $6-10{ }^{\circ} \mathrm{C}$ não influenciou significativamente os resultados de dureza.

Pode também ser observado na Tabela 7 um acréscimo significativo na média de dureza tanto na ZF como na ZTA para todos os procedimentos em comparação aos metais de base utilizados (chapa e tubo). Os valores de

Tabela 7. Média, desvio padrão e variância do ensaio de dureza vickers com carga de 10 kgf.

\begin{tabular}{ccccc}
\hline & Região & Média (HV) & Desvio Padrão & Coef. de Var. \\
Metal Base & Tubo & 187 & 15 & 3 \\
& Chapa & 229 & 16 & 3 \\
\multirow{2}{*}{ F11 } & ZTA & 255 & 25 & 10 \\
& ZF & 269 & 23 & 8 \\
Q11 & ZTA & 263 & 14 & 5 \\
& ZF & 280 & 12 & 4 \\
\multirow{2}{*}{ F6 } & ZTA & 263 & 18 & 7 \\
& ZF & 283 & 19 & 7 \\
& ZTA & 280 & 15 & 5 \\
& ZF & 287 & 9 & 3 \\
\hline
\end{tabular}


dureza obtidos nas 4 juntas soldadas também são bem superiores aos procedimentos de soldagem convencional, onde os consumíveis de soldagem utilizados (TIG e eletrodo revestido) apresentam dureza entre 180 e $220 \mathrm{HV}[8,9]$.

Os resultados da dureza ratificam os valores obtidos nos ensaios de tração (veja Tabela 6) tendo sido observado um aumento da dureza acompanhado com um aumento do limite de resistência e queda da ductilidade.

Ensaio de Impacto: os resultados obtidos no ensaio de impacto são mostrados na Tabela 8. A energia absorvida (EA) pelo metal base foi $268 \mathrm{~J}$.

Tabela 8. Resultados do ensaio de impacto Charpy $\mathrm{V}$ a $0{ }^{\circ} \mathrm{C}$.

\begin{tabular}{ccccccccc}
\hline CP & Dimensão (mm) & $\begin{array}{c}\text { Localização do } \\
\text { Entalhe }\end{array}$ & \multicolumn{2}{c}{ Energia Absorvida (J) } & $\begin{array}{c}\text { Média } \\
\text { (J) }\end{array}$ & $\begin{array}{c}\text { Média da EA } \\
\text { Proporcional ao } \\
\text { Padrão (J) }\end{array}$ & $\begin{array}{c}\text { API 5L PSL-2 } \\
{[17](J)}\end{array}$ \\
MB & $55 \times 10 \times 10$ & MB & 266 & 266 & 273 & 268 & 268 & 27 (mín) \\
Q6 & $55 \times 10 \times 2,5$ & ZF & 28 & 30 & 39 & 32 & 128 & \\
& $55 \times 10 \times 2,5$ & ZTA & 38 & 34 & 34 & 35 & 140 & \\
F6 & $55 \times 10 \times 2,5$ & ZF & 28 & 31 & 29 & 29 & 116 & \\
& $55 \times 10 \times 2,5$ & ZTA & 31 & 29 & 30 & 30 & 120 & 27 (mín) \\
\multirow{2}{*}{ Q11 } & $55 \times 10 \times 7,4$ & ZF & 209 & 201 & 203 & 204 & 272 & \\
& $55 \times 10 \times 7,4$ & ZTA & 203 & 216 & 199 & 206 & 274 & \\
F11 & $55 \times 10 \times 7,4$ & ZF & 237 & 273 & 279 & 263 & 355 & \\
\hline
\end{tabular}

Os procedimentos $\mathrm{Q} 6 \mathrm{e} \mathrm{F} 6$, com $6 \mathrm{~mm}$ de espessura, apresentaram EA convertida inferior ao do metal base e aos procedimentos $\mathrm{Q} 11$ e F11, com $11 \mathrm{~mm}$ de espessura. Mesmo com esta redução a média de energia absorvida foi superior ao mínimo de $27 \mathrm{~J}$ estabelecido pela norma API 5L PSL-2 [17]. Assim, tanto o arrefecimento como a temperatura do fluido interno não alteraram significativamente a tenacidade ao impacto da ZF e da ZTA.

Os resultados dos ensaios apresentados acima (ensaios não destrutivos, dobramento, fratura, tração, dureza e impacto) permitem aprovar e qualificar o procedimento de soldagem conforme ASME seção IX [12] para a soldagem em operação de tubos com $6 \mathrm{~mm}$ e $11 \mathrm{~mm}$ de espessura com fluido interno até a temperatura mínima de $6-10^{\circ} \mathrm{C}$.

Microstrutura: foi avaliada a amostra F6, que apresentou maior dureza na ZF. A microstrutura do MB (tubo) é constituida de estrutura tipicamente hipoeutetóide, composta por ferrita e perlita em proporções similares, Figura 7. A ZF é constituída em sua maioria de ferrita com segunda fase alinhada e em menor quantidade ferrita poligonal intragranular apresentando ainda agregados ferrita-carboneto, Figura 8. A região de grãos finos (RGF) da ZTA, Figura 9, é constituída de grãos de ferrita com tamanho de grão bem inferior ao apresentado pelo metal

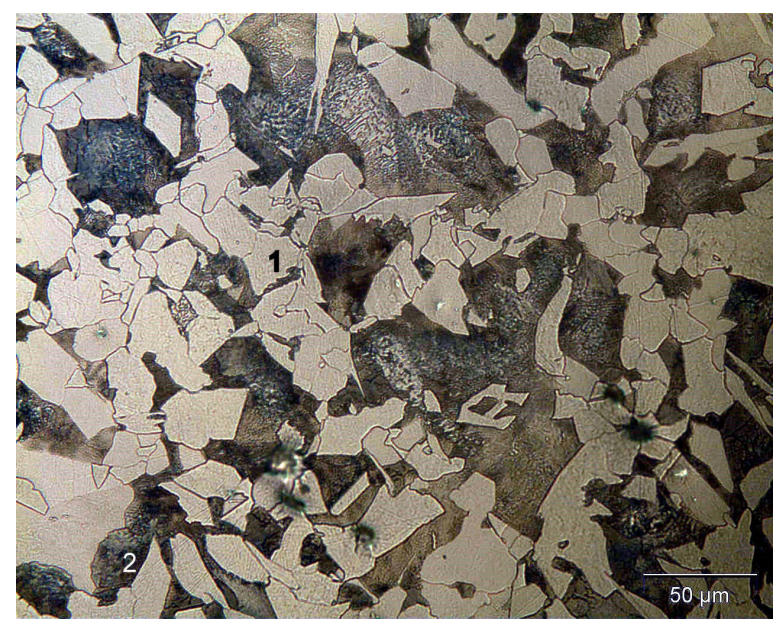

Figura 7. Metal base (chapa) 400X. 
Efeito do Arrefecimento Causado pelo Fluido Durante a Soldagem em Operação em Tubulações com Espessura de Parede de 6 e $11 \mathrm{~mm}$

base, Figura 7. A região de grãos grosseiros (RGG) da ZTA, Figura 10, é constituída predominantemente de ferrita de Widmanstatten com menor quantidade de ferrita poligonal intragranular. Não há evidências de fases frágeis. A microestrutura obtida é compatível com os resultados de dureza (Tabela 7) e tenacidade ao impacto (Tabela 8).

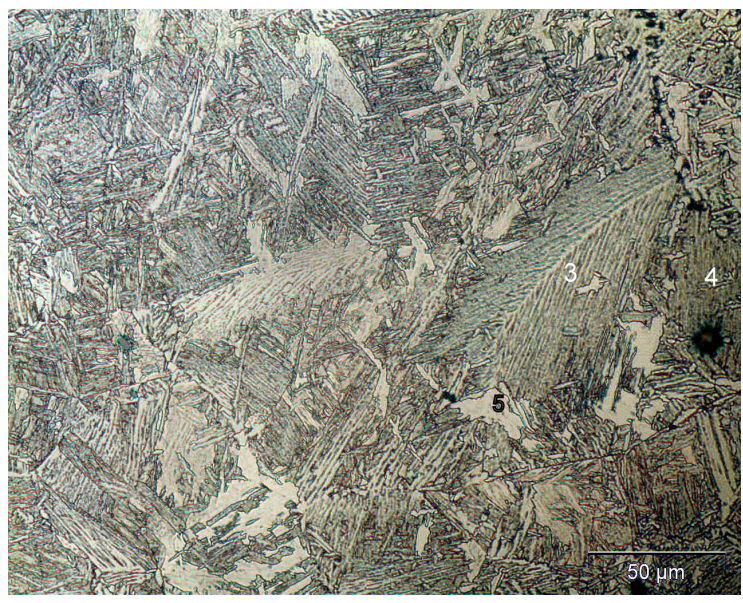

Figura 8. Zona fundida 500X.

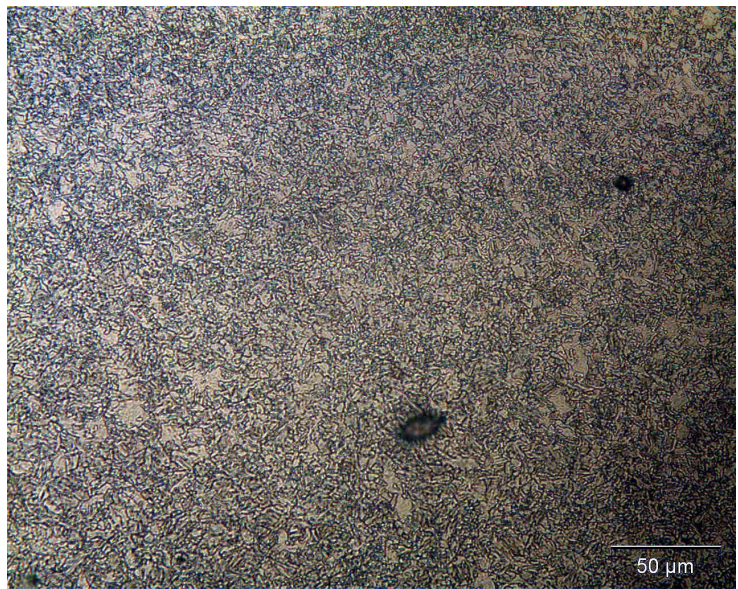

Figura 9. Região de grãos finos da ZTA (tubo) 400X.

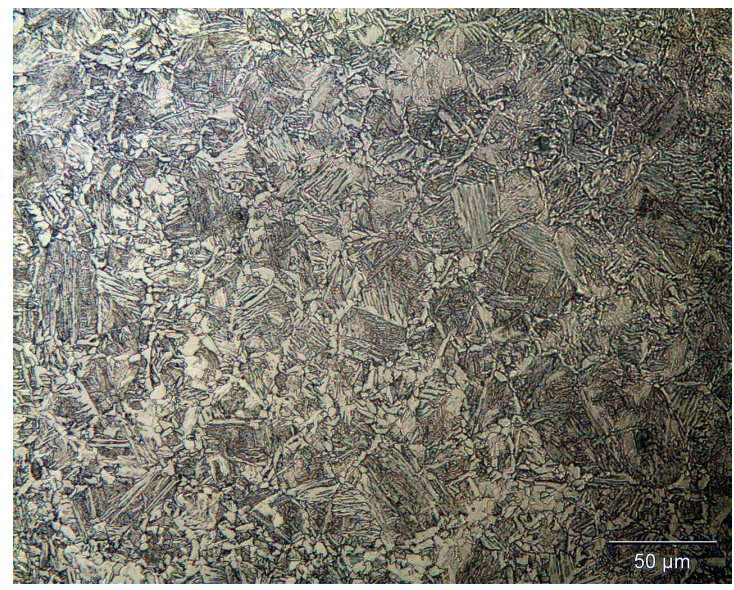

Figura 10. Região de grãos grosseiros da ZTA (chapa) 400X. 


\section{Conclusões}

Ao avaliar na soldagem em operação a influência da temperatura do fluido de arrefecimento em contato com a parede interna em tubos de $6 \mathrm{~mm}$ e $11 \mathrm{~mm}$ de espessura, utilizando os processos de soldagem TIG (GTAW) e Eletrodo Revestido (SMAW) foi possível concluir que:

Na soldagem em operação, o resfriamento causado pelo fluido em circulação, elevou significativamente a taxa de resfriamento na superfície interna do tubo, quando comparado à soldagem convencional, sem arrefecimento.

A taxa de resfriamento apresentada pelo tubo com $6 \mathrm{~mm}$ de espessura foi superior à do tubo com $11 \mathrm{~mm}$ de espessura. Porém, houve evidencias que o efeito do arrefecimento do fluido no interior do tubo foi mais significativo que a espessura da parede do tubo no aumento da taxa de resfriamento.

A temperatura do fluido em circulação no tubo exerceu papel secundário no aumento da taxa de resfriamento e na redução da temperatura máxima na parede interna do tubo.

O arrefecimento causado pelo fluido provocou um aumento na dureza da ZF e ZTA, reduziu o alongamento no ensaio de tração, porém ainda em valores adequados. Estes comportamentos foram mais observados no tubo de menor espessura, de $6 \mathrm{~mm}$.

Foi possível, pelos resultados dos ensaios não destrutivos e ensaios mecânicos obtidos, qualificar os procedimentos de soldagem, com base nas normas especializadas neste processo.

Com os procedimentos de soldagem adotados, não é necessária a adoção de cuidados especiais quanto à possibilidade de perfuração e vazamento de fluido durante a soldagem em operação, visto que a temperatura máxima na parede interna do tubo foi de $558^{\circ} \mathrm{C}$.

\section{Referências}

[1] Küchler MM. Aplicação da técnica de dupla camada na soldagem de dutos em operação [dissertação de mestrado]. Porto Alegre: Universidade Federal do Rio Grande do Sul; 2009.

[2] Coe FR. Welding steels without hydrogen cracking. Cambridge: The Welding Institute; 1973.68 p.

[3] Modenesi PJ. Soldabilidade dos aços transformáveis. Belo Horizonte: Departamento de Engenharia Metalúrgica, Universidade Federal de Minas Gerais; 2006. 71 p.

[4] Bruce WA. Procedure qualification for welding onto in-service pipelines. In: American Petroleum Institute. API Pipeline Conference; 2002 September-October 29-03; Washington, D.C., USA. Washington: API; 2002.

[5] Bruce WA. Overview of in-service welding research at EWI. In: Edison Welding Institute. First International Conference on Welding Onto In-Service Petroleum Gas and Liquid Pipelines; 2000 March 6-8; Wollongong, Australia. Ohio: EWl; 2000.

[6] Faria P, Soares JF, Araufo FFS, Paranhos RPR. Soldagem em Operação: Parte 1. Efeito do Arrefecimento Causado pelo Fluido em Tubulação de Espessura $11 \mathrm{~mm}$. Soldagem \& Inspeção. 2012;17(4):280-287. http://dx.doi.org/10.1590/ S0104-92242012000400002.

[7] American Society for Testing and Materials. ASTM A105: standard specification for carbon steel forgings for piping applications. West Conshohocken: ASTM; 2010. 5 p.

[8] American Welding Society. AWS A 5.18: specification for carbon steel electrodes and rods for gas shielded arc welding. Miami: AWS; $2005.44 \mathrm{p}$.

[9] American Welding Society. AWS A 5.1: specification for carbon steel electrodes for shielded metal arc welding. Miami: AWS; 2005. 55 p.

[10] American Petroleum Institute. API 1104: standard for welding pipe lines and related facilities. Washington: API; 2010. 50 p.

[11] American Society for Mechanical Engineers. ASME Section V: non destrutive examination. USA: ASME; 2007. 304 p.

[12] American Society for Mechanical Engineers. ASME Section IX: qualification standard for welding and brazing procedures, welders, brazers, and welding and brazing operators. USA: ASME; 2008. 245 p.

[13] American Society for Testing and Materials. ASTM A 370: standard test methods and definitions for mechanical testing of steel products. West Conshohocken: ASTM; 2008. 47 p.

[14] American Society for Testing and Materials. ASTM E 92: standard test method for vickers hardness of metallic materials. West Conshohocken: ASTM; 2003. 9 p.

[15] American Society for Mechanical Engineers. ASME B 31.1: process piping. USA: ASME; 2010. $386 \mathrm{p}$.

[16] Petrobras. N-2163: soldagem e trepanação em equipamentos, tubulações industriais e dutos em operação. Rio de Janeiro: Petrobras, 2008.

[17] American Petroleum Institute. API 5L PSL-2: specification for line pipes. Washington: API; 2009. $186 \mathrm{p}$. 